\title{
THE INTERPLAY OF SOCIAL POLICY AND SUICIDE IN GILGIT-BALTISTAN REGION: WHAT WENT WRONG?
}

\begin{abstract}
Suicide has emerged as a serious social issue in the region of Gilgit-Baltistan (GB) due to consistently rising suicidal thoughts and actions among young people. However, suicidal behaviours remained an under-researched subject in Pakistan. Consequently, the growing suicidal inclination in the GilgitBaltistan region has not yet received the due consideration of policy analysts and social scientists in general. Meanwhile, suicide has emerged as a leading cause of death among youth and a major public health issue signifying serious problems in the socio-cultural system of the country. The current research explores the socio-economic factors prompting individuals to commit suicide. Furthermore, the study asks what role the GB government and other stakeholders of social policy are playing in understanding and eliminating the tendency of suicidal ideation. The research was conducted in the Ghizer district using qualitative research methodology. Case study data were collected using in-depth interviews with suicide survivors and friends, parents and family members of those who committed suicide. The findings of this research reveal that forced marriages, educational pressures, financial crises, family conflicts and societal restrictions are the leading causes of the mounting suicides in the region. The government was unable to formulate a specific social policy to comprehend the causes of suicides in the area, nor did it make any substantial intervention to end this endemic trend. Finally, the study suggests that there is a dire need to conduct culture-specific research on this vital issue to grasp the grassroots understanding in order to formulate successful policy interventions.
\end{abstract}

Kanwal Shahzadi- MPhil, Department of Government \& Public Policy, National Defence University, Islamabad, Pakistan. Email: kanwalshahzadi63@live.com

Fiaz Hussain - PhD, Assistant Professor, Department of Public Administration, Fatima Jinnah Women University, Rawalpindi, Pakistan. Email: fiazhussain@fjwu.edu.pk

Muhammad Bilal-PhD, Head of Department of Anthropology, Fatima Jinnah Women University, Rawalpindi, Pakistan. Email: Email: anth.fjwu@gmail.com 
Keywords: Suicide, Social Policy, Social Pressures, Policy Failures, GilgitBaltistan

DOI: $10.17323 / 727-0634-2021-19-3-509-522$

Suicides and suicide attempts worldwide have been challenging the state's claims of providing safety and security to its people. In this regard, social policy can have a momentous impact upon suicide prevention initiatives. The government's proactive role is the foremost prerequisite to develop an inclusive social policy framework for suicide prevention and fulfilling fundamental needs through social welfare and social protection programmes (Alcock 2014). In addition, informed social policies aid in the dissemination of resources by addressing severe social issues like illiteracy, poor health, social insecurity, homelessness and poverty, which constrain the goal of developing a healthy society (Dennison 1975; Spicker 2011). Although the state is the principal institution of social policy formulation, other institutions such as non-governmental organizations (NGOs), private sector and international research organizations also contribute towards better welfare of people. Social policies usually address specific social problems. Policy interventions are envisioned to eradicate the circumstances that create problems. There are six primary objectives of social policy: human wellbeing, poverty eradication, social protection, human rights promotion, the fight against social exclusion and the conservation of natural resources (Hall, Midgley 2004). The accomplishment of these goals does not only require a stable state, but also the contribution of civil society, the private sector and international development institutions (Manning 2012; Zutavern, Kohli 2012). We argue that of the above six objectives, poverty eradication is the primary goal of social policy. Social policy is not just about the provision of welfare to people to keep them afloat; part of it is also social protection which is an imperative constituent for the prosperity of ordinary citizens. Social protection aims at preventing, managing and overcoming those situations which unfavourably affect the wellbeing of people, through social insurance, social assistance and local market intervention to provide the fundamental amenities essential to live a good social life (Esping-Andersen 1990).

One of the severest outcomes of poor social protection is the spread of suicide. Although suicide is a problem in developed countries, a more significant part of the global suicide burden is shared by low- and middle-income countries and is connected to poverty. Socio-economic factors are the main reasons for increased rates of suicide among adolescents in developing countries (Agerbo et al. 2007; Ferretti, Coluccia 2009). The growing level of suicide in a society indicates that the social structure is unbalanced as shown by classical sociological studies (Durkheim 1951) and it must be dealt with as a common problem (Flavin, Radcliff 2009). In Pakistan, according to the World Health Organization (WHO 2014), national suicide rates remain hidden due to social, legal and reli- 
gious concerns. What is known is that people do just not commit suicide because of mental illness; there are social and family-related factors which force people to take their lives (Holden 1986; Pridmore 2000). For example, as our research shows, in the context of Gilgit-Baltistan, forced marriages are one of the leading causes of attempted suicide. Furthermore, it is considered the second most cause of death among the 15-29 age group (Chan 2014).

According to one estimate, twenty people on average commit suicide annually in Gilgit-Baltistan (GB) which is the focus of our study (Shah 2018). There are no reliable sources available which could help to ascertain the actual number of suicides. Very few cases are registered at police stations and the actual reasons for the suicide attempts are not recorded because of cultural and religious barriers. The primary field of this study is the Ghizer district in GB, where the highest percentages of suicide cases are reported annually. According to the HRCP Gilgit-Baltistan, there are between 15-20 suicides every year. Figure 1 shows the number of suicide by year in the region. While aggregated statistics are limited and incomplete and do not show the full prevalence of suicide cases in the area, they indicate that the number of suicides has declined in the last year in GB. However, as a percentage of the population of the area, suicide rates are still rising. Thus, our research explores what socio-economic factors are contributing toward the mounting suicide trends in this region and if there is any social policy in place to deal with this issue. We suggest some policy measures to the government of GB in order to deal with this threat.

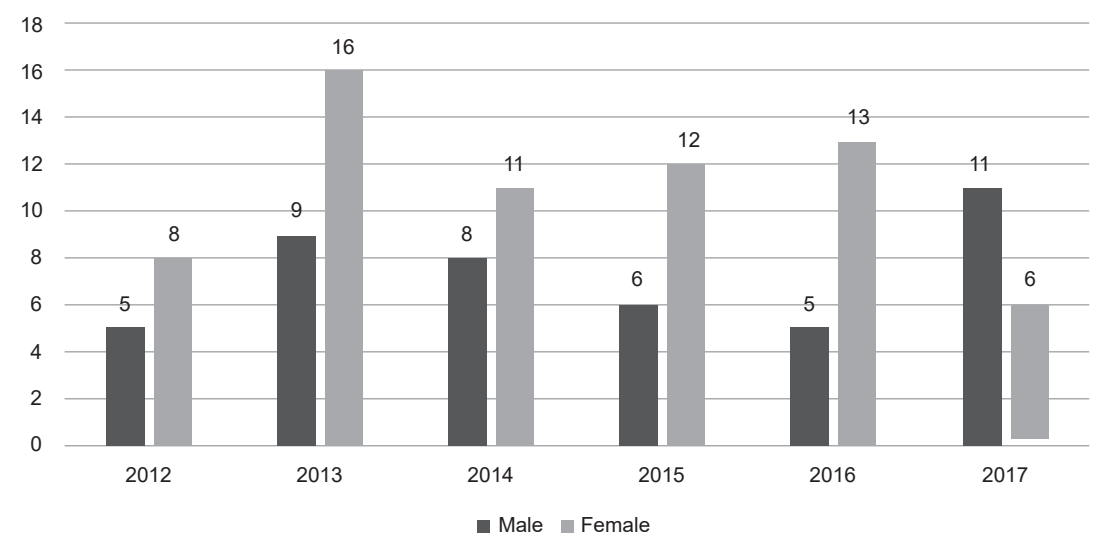

Figure 1. Suicide Trends in District Ghizer, Gilgit-Baltistan (Year-Wise Suicide Numbers)

Source: Authors compilation based on data obtained from Karakoram International University, Gilgit-Baltistan, Pakistan.

One note about the status of the region before presenting our research. GB became a self-governing region following the Gilgit-Baltistan Reforms and 
Self-governance Order 2009, which were enacted by Pakistan's president. It has an independent Legislative Assembly and Council. The Supreme Appellate court of Gilgit-Baltistan is independent, and it is the highest court in the region. The constitutional status of GB is still ambiguous, and it is governed through orders and notifications issued by the Federal Government in Islamabad. In order to ensure good governance at the grassroots level, the Local Government Act 2014 was passed by the GB Legislative Assembly. Under the Government Act, primary education and health care at the local level are the responsibility of local government. Furthermore, Social Welfare and Community Development Policy directs the local council to assume responsibility for the poor, families of military veterans, women and children. In addition, Jirga Anjumans (traditional assemblies of elders) were created at the local level under the Local Government Act 2014 to resolve disputes at the local level without charges.

\section{The Interplay of Suicide Attempts and Socio-Cultural Factors}

Research on socio-political and economic indicators of suicide focus on the economic setting and economic practices in a region. There is an association between economic factors and suicide, more precisely unemployment is considered a significant influence (Ceccherini-Nelli, Priebe 2010). Researchers have proved this relationship both through normative and empirical studies: a $1 \%$ increase in unemployment can raise the suicide rate by $0.79 \%$ among persons younger than 65 (Stuckler et al. 2009). However, there are other economic factors like poverty, financial loss and debt, which also influence suicide rates (Haw et al. 2015). As suicide is a social phenomenon, researchers look into society to find the social factors of suicide. Thus, socio-economic status affects the rates of suicide and social policy measures are essential for the prevention of suicidal behaviour (Rezaeian et al. 2005). Furthermore, researchers have found that there is a relationship between suicide and one's surrounding. Suicide rates are related to the environment where we live and the economic status of the region (Cheong et al. 2011). In this respect, there are some peculiarities for suicide factors in Asia: namely, traditional values, rapid economic changes in the global market, availability and accessibility of suicide methods, life stress (like family conflict, unemployment and financial issues), which are higher in Asia as compared to Western countries (Chen et al. 2012).

Suicide is also a gendered problem. Hence, social factors which lead to suicidal behaviour are family problems, unsuccessful marriages, high expectations from romantic relationships and, most of the time, poverty- which can be connected to gender and more general factors (Keyvanara, Haghshenas 2010). Scholars also suggested that radical changes in society and the gap between traditional and modern values and attitudes affect the suicide attempts, especially among women (Haarr 2010). Add to this picture domestic violence as one of the indicators with women who are abused being more likely to attempt suicide (Haarr 2010). 
Lakshmi Vijayakumar (2004) suggests that there is an urgent need for suicide prevention in developing countries. The study finds that $73 \%$ of suicides in developing countries are not recorded. Therefore, suicide prevention in developing countries should be a social and public objective of the government. Developed countries have put in place different prevention programs to control suicide rates, whereas it is a neglected issue in developing countries (Khan 2005). Governmental and non-governmental organizations in developing countries need to work together in order to overcome the challenge. At the same time, no one approach can overcome suicide issues alone (Ayuso-Mateos 2019). There are so many social and psychological factors which cause suicidal behaviour or suicide attempts. Likewise, the explanatory model in psychology, for example, focuses on improvements to people's mental health, whereas other approaches support alternative models which highlight social indicators as causes of suicide (Ibid). The social determinants of suicide are equally important as psychological factors. Therefore, each area needs equal attention, and all the approaches should be combined to overcome the rates of suicide in any area.

It is essential to consider suicide as a public problem. Alexander Tsai et al. (2015) have evaluated the impacts of social integration on suicide among women in the United States. This statistical study based on primary sources successfully analyses that the number of suicide cases decreases with increasing rates of social assimilation: social interaction in the form of relationships, social networking and community participation can decrease the incidence of suicide. However, the authors fail to explain that negative interactions can produce the opposite result. Moreover, a recent policy paper from Canada discusses that reports of suicide in media have an impact on people who are susceptible to suicide and increase the risk of people taking their own lives (Sinyor et al. 2018). They also suggest that reports on suicide can glamourize the different methods used to attempt suicide. Similarly, they argue that media reports on unusual ways of taking one's own life have dramatically increased the number of deaths. Instead of giving coverage to suicide, the media should focus on people who overcome their suicidal thoughts. It will give a positive message, and it will help lower suicide rates.

The governments of developing countries are taking significant steps to prevent suicide, too. Bhutan, a South-Asian developing country, has recognized suicide as a severe public problem (Dorji et al. 2017). A three-year action plan was prepared in 2015 to address the issue and local governments are assuming responsibility for implementing the suicide prevention policies at the local level. Indeed, developing countries should also take the opportunity to build and strengthen suicide prevention policies with the help of both central and local government. Milad Nazarzadeh et al. (2013) determine the occurrence of factors of suicide in Iran such as marital problems, economic constraints and educational failures. However, another study emphasizes the role of social protection in minimizing the adverse effects of economic conditions on suicide (Kim 2018). Social protection programmes can target the suicide issue and include policies 
which significantly and positively influence the well-being of citizens. According to the social integration method and the social regulation method, there is an inverse relationship between suicide and social protection (Ibid). Therefore, social protection programmes can help overcome suicide rates in a country.

There is very limited literature available on the incidence of suicide in Pakistan. Authors like Murad Moosa Khan et al. (2008) identify the common risk factors of suicides in Pakistan such as psychiatric disorders, marriage problems, unemployment and other stressful life events. Samina Sher and Humera Dinar (2014) study the social and cultural issues which influenced female suicide rates in the region of Ghizer and find that burdens of modernization, academic pressure, materialism, social competition and feelings of underperforming are the main reasons behind the suicide of women in the region. Another study examines the relationship between public policy and suicide, and the findings show that countries having more lavish expenditure on social welfare and more liberal public policy have lower suicide rates (Flavin, Radcliff 2009).

Recent research conducted in GB (Bibi et al. 2019; Mahsud, Ali 2018; Rahnuma et al. 2017) highlight various factors engendering situations eventually leading towards suicide. These include poor family relatiionships, lack of communication between parents and children, a normative clash between orthodox and heterodox values, failure in an intimate relationship and academic pressure as the prime reasons for suicidal ideation. Khan (2018) explains that in Ghizer alone, there are 203 stories of those who have committed suicide between 2006 and 2017. This research suggests that parental education, awareness and resources are pivotal for parental sensitization to provide them with guidance for better communication and management particularly in cases where a child may be at risk for suicide. Furthermore, developing an understanding of early suicide signs is important for the timely management of the problem. Every potential suicide victim initially goes through suicidal ideation and shows suicide signs that need to be understood and dealt with on time.

\section{Research Methodology}

A qualitative research design was used to understand the socio-economic dynamics of suicide in Ghizer, one of the districts of Gilgit-Baltistan region of Pakistan which is home to 170,000 people. This small region has sent shock waves across the country due to high suicide rates: an average of twenty women attempt suicide each year, the highest rate in Pakistan (Bibi 2019). According to Ghizer Times, from 1996 to 2010, more than 300 cases of suicide were reported at various police stations of Ghizer. However, it is widely believed that the figure might be much higher and actual prevalence and authentic data is not available due to socio-cultural factors and family threats (Khan 2018). According to mass media reports, 340 women committed suicide in the period from 2005 to 2011 in the Ghizer district, 125 people have committed suicide between 2010 and 2017 in the region (Pamir Times 2018). 
In the present research, in-depth interviews were conducted to collect case studies of suicide incidents. In order to obtain relevant cases, a purposive sampling technique was used. This technique helped selecting respondents who were the survivors of suicide attempts or the relatives of suicide victims, enabling us to acquire knowledge about the reasons behind suicidal behaviour and them to talk about this issue with someone without judgement. In result, twenty in-depth interviews were conducted. Most of the interviews were conducted in the Khowar language, which is one of the local languages and is understood by most of the people in the region. These interviews were recorded after obtaining the informed consent of respondents and later transcribed for thematic analysis. Confidentiality of data and anonymity of the interviewee was safeguarded throughout the research. No psychological or physical harm was caused to the participants.

Interview guides were developed in English, which were translated into the Khowar language after a pilot study that was designed to improve the comprehension of the questions to respondents. There were blocks of questions to elicit from participants various facets of the research problem to understand the socio-economic influences leading individuals towards committing suicide. However, care was taken not to ask such direct questions that could lead towards the reliving of traumatic suicidal experiences. The various set of questions in the interview guide aimed at exploring the social, economic, religious and familial reasons responsible for the persistently high rate of suicide in the region. Other questions focused on the role of the GB government and other stakeholders to help us understand and reduce the tendency of suicidal ideation. The last set of questions was devoted to possible intervention measures aimed at minimizing suicidal attempts.

Thematic analysis was employed to analyse the data gathered through indepth interviews and case studies. The objective of thematic analysis was to categorize themes from the interview transcripts. The prominent patterns were reviewed for the construction of themes in order to present the data in an organized way. It was an attempt to generate a thick description and interpretation of the participants' perspectives using the native lens (Maguire, Delahunt 2017). From two-level themes, semantic and latent, the latent level was chosen to explore underlying facts and concepts, which were beyond the surface meaning (Clarke, Braun 2013). In order to conduct a coherence thematic analysis, the six-phase guideline was utilized (Ibid).

\section{Findings and Discussion}

Earlier research identified numerous factors which are responsible for the growing suicide rates in the region of GB, such as poverty, educational barriers, cultural pressure, male dominance, lack of personal freedom, mental illness, drug abuse, social competition and discourses of modernization. Sher and 
Dinar (2014) categorize these factors into three groups: namely, social, cultural and psychological factors. Poverty has been a central issue for social policy. Unfortunately, it is one of the main causes of suicide in GB. Along with the hardships of weather and natural disasters, poverty is an additional burden for people in the region. The finance division of the government of Pakistan (2018) reports that the national poverty rate is $24.3 \%$, whereas it stands at $30.7 \%$ in rural regions, including GB. Although social policy frameworks are oriented towards targeting vulnerable communities, people are still suffering from poverty in GB. The extremely harsh climate of the region makes it difficult for farming. In this case, the inhabitants of GB see educating their children as the only opportunity to escape poverty, but if families are unable to afford education for their children, they get depressed. Therefore, they consider suicide as an escape: many respondents, during the interviews, regretfully said that suicide is a better option for them, it is better to die than to live poor.

Although different rural development programs have been introduced in the region, the government has failed to improve the living standards of these vulnerable people. Every year due to natural disasters like floods and earthquakes, momentous destruction takes place in the region, which further increases vulnerability and misery in the area. Even if the government allocates the budget for development in GB, there are no proper checks and balances and the government funds do not make it to the poor because of corruption and ineffective implementation; therefore, no positive impact can be seen. Moreover, the Federal Government also has launched a number of initiatives to reduce poverty and enhance socio-economic indicators. According to Annual Plan 2015-2016 (Ministry of Planning and Development 2016), 2000 million Pakistani rupees was allocated for Development Programs and Projects for the year 2014 to 2015 in GB, but their effective utilization is still a question. Social policy is a mechanism used in converting the goals and objectives into practical actions that can affect the lives of people positively. In GB, the issue of the proper implementation of social policies remains shaky. Government and other stakeholders of the social policy are responsible for strengthening producers and improving the underprivileged people's access to productive resources and financial services.

Much of the literature above provides strong evidence that there is a positive relationship between unemployment and suicide. The longer a person is unemployed, the higher will be the chances of a suicide attempt. Similarly, GB is a region where most of the people are dependent on agriculture to earn a livelihood for their families. Office jobs are uncommon, most educated people migrate towards metropolitan cities in search of jobs. Likewise, one of the suicide survivors described his struggle through life. According to him, he went to the city in search of a job. It was a hard time for him being unemployed, he added:

There are no employment opportunities here, so we leave our homes and get into such troubles. I was in a great depression; my family was asking what I was doing there. I was not in a situation to come home, how could I come? I 
was struggling to find a job the whole day, and at the end, I used to return in the same condition, jobless. I was helpless, so I swallowed pills, high dose.

It is challenging for people with lower levels of education to find work. GB is rich in natural resources; nevertheless, this could not provide employment prospects to the locals. The lack of resources and training skills hindering individuals from securing good jobs. At the same time, social policy formulation and implementation is the job of government and other responsible institutions. The government, along with NGOs such as the Aga Khan Rural Support Program (AKRSP), is working to overcome unemployment through different programs. Nevertheless, unemployment remains one of the main reasons for suicide attempts in the region.

In GB, societal pressures such as arranged marriages, demands for good grades in schools and anxiety of earning a good livelihood to support the family are becoming the reasons of suicide. Adherence to traditional way of life seriously compromises the civil rights of ordinary people. There is a generation gap between those who follow traditions and those who do not find these traditions legitimate anymore and this leads to family conflicts. Forced marriages, early marriages and pressure from parents to get good grades are among the most wide spread societal pressures. Traditional values and customary laws are still valued, and many people are resistant to change existing customs even if they are against the very spirit of human rights. Human rights protection is another essential goal of social policy, so accountable institutions are meant to work on the various social dimensions of this objective. Yet, there is an evident conflict in the region.

Another problem identified during the current research is that a large number of women in GB face domestic violence, and when it becomes insufferable, they end their lives. It is found that women bear a high level of domestic violence in GB (AGHE 2006). Notably, out of the total number of suicides of women, $73 \%$ are married women and mostly come from the Ghizer District (Khan et al. 2009). The government has shown no initiative to overcome the issue of domestic violence in GB. There is a lack of awareness of women's rights in the area. People, in general, do not consider violence against women as a violation of fundamental human rights. Despite that, the government is not taking any action to raise awareness among locals. A case was identified from the Yasin region of the Ghizer District, where a young married girl hanged herself because her father-in-law and mother-in-law were assaulting her verbally and physically. In such circumstances, women consider themselves insecure and extremely vulnerable. During the fieldwork, forced marriages emerged as another important reason for the growing number of suicide attempts. A father confesses that it was his fault that his daughter committed suicide:

It is my fault, and I did not think about my daughter's future. Engagement at $7^{\text {th }}$ grade would result in a marriage in 10th grade. My daughter was too young to get married, why I did not think about that? 
Forced marriages are common in more traditional regions of GB where girls are forced into marriages. The girls of the area are unaware of the laws and their rights pertaining to marriage. The most common reason for child marriages in GB is weak legislation. Early age marriage has become a dilemma in Pakistan, whereas lawmakers of Gilgit Legislative Assembly banned a Legislative Bill on child marriage, declaring it as an un-Islamic measure (Mir 2015).

Parents' unrealistic expectations of their children by pressurizing them to achieve high grades is identified as another indicator of youth to commit suicide. A college student committed suicide since his parents were consistently forcing him to secure good grades and insulting him while quoting the examples of other students. Consequently, he could not bear this frustration and committed suicide. Despite the harmony and family integration in GB culture, it is found that family conflicts are associated with suicide risks among the ordinary people in the region. It is imperative to resolve these issues for the sake of development in the region. Government and other social policy stakeholders should intervene to overcome the causes of suicide.

\section{Conclusion}

Our research shows that factors such as poverty, unemployment, forced marriages, family conflicts, educational pressures and societal restrictions are contributing to suicide attempts in the region of GB. Recent surveys of various organizations such as Hussain's Safety Life Organization and Human Rights Commission of Pakistan (HRCP) show that the highest number of suicide cases were reported in the Ghizer district of GB (Shah 2018). Therefore, the local government's intervention could reduce those contributing factors responsible for escalating this social problem. Although NGOs are working in this area, without the support of the local government, they are unsuccessful. Meanwhile, government policies have remained ineffective because of poor implementation. The local government needs to develop a partnership with NGOs, civil society, community-based organizations and other private sector organizations for a successful intervention.

Moreover, the first step the government may take is to increase social protection programs in order to overcome poverty and vulnerability in GB. Secondly, the government and other stakeholders may generate employment opportunities for young people. The private sector may be encouraged to invest in GB to overcome the unemployment rate. Thirdly, the government can make some effective policies to address women related issues like forced marriages, domestic violence and implement existing laws effectively. Furthermore, NGOs can also play their role to deal with suicide-related issues in the form of community-level suicide prevention programs in different regions of GB. In addition, school-based suicide awareness programs can be introduced in all public and private schools of the region, enabling individuals to deal with 
stress and depression. At the same time, NGOs and other civil societies can play an active role in overcoming suicide through counselling. Similarly, crisis centres and free trauma helpline services can be provided to deal with the stress of individuals in the region.

The present study highlights the critical gap between the social policy and suicide management while highlighting general unfamiliarity of local issues creating an environment which is persistently creating high suicide rates in the GB region. The lack of cultural cognition in policy formulation and weak implementation have been creating impediments in reducing the consistent suicide trend in the Ghizer district of GB. Therefore, further research may be conducted in GB in order to determine the magnitude of the suicide problem. This, in turn, can eventually help to formulate policy interventions to reduce the suicide tendency in the region.

\section{References}

Agerbo E., Sterne J. A., Gunnell D. J. (2007) Combining Individual and Ecological Data to Determine Compositional and Contextual Socioeconomic Risk Factors for Suicide. Social Science \& Medicine, 64 (2): 451-461.

AGHE (2006) Violence Against Women in Northern Areas of Pakistan. In: Seminar Report: White Ribbon Day 2006. Ghizer District: Northern Areas, Association of Global Humanists and Ethics (AGHE) \& Ghizer Rural Advancement Foundation (GRAF).

Alcock P. (2014) Social Policy in Britain. Cham: Macmillan.

Ayuso-Mateos J.L. (2019) Suicide Prevention: Towards an Evidence-Based Policy. Epidemiology and Psychiatric Sciences, 28 (5): 467-468.

Bibi R., Shah M., Khan Y. (2019) Exploring the Social Determinants of Female Suicide in District Chitral, Pakistan. Pakistan Journal of Society, Education and Language, 5 (1):73-81.

Bibi S. (2019) Exploring the Rising Trend of Suicide in Gilgit-Baltistan Region. Journal of Pioneering Medical Sciences Blog. Available at: https://blogs.jpmsonline.com/2019/02/23/ exploring-the-rising-trend-of-suicide-in-gilgit-baltistan-region-of-pakistan/ (accessed 05 March 2020).

Ceccherini-Nelli A., Priebe S. (2010) Economic Factors and Suicide Rates: Associations Over Time in Four Countries. Social Psychiatry and Psychiatric Epidemiology, 46 (10):975-982.

Chan M. (2014) First WHO Report on Suicide Prevention. Available at: http://apps.who.int/ iris/bitstream/10665/131056/1/9789241564779_eng.pdf?ua (accessed 16 September 2019).

Chen Y.Y., Wu K.C C., Yousuf S., Yip P. S. (2012) Suicide in Asia: Opportunities and Challenges. Epidemiologic Reviews, 34 (1): 129-144.

Cheong K., Choi M., Cho B., Yoon T., Kim T., Kim Y., Hwang I. (2011) Suicide Rate Differences by Sex, Age, and Urbanicity, and Regional Related Factors in Korea. Journal of Preventive Medicine and Public Health, 45 (2): 70-77. 
Clarke V., Braun V. (2013) Teaching Thematic Analysis: Overcoming Challenges and Developing Strategies for Effective Learning. The Psychologist, 26 (2): 120-123.

Dennison D. V. (1975) An Approach to Social Policy. Dublin: National Economic and Social Council.

Dorji G., Choki S., Jamphel K., Wangdi Y., Chogyel T., Dorji C., Nirola D. (2017) Policy and Governance to Address Depression and Suicide in Bhutan: The National Suicide-Prevention Strategy. WHO South-East Asia Journal of Public Health, 6 (1):39-44.

Durkheim E. (1951) Suicide: A Study in Sociology. Glencoe: Free Press.

Esping-Andersen G. (1990) The Three Worlds of Welfare Capitalism. Cambridge: Polity Press.

Ferretti F., Coluccia A. (2009) Socio-Economic Factors and Suicide Rates in European Union Countries. Legal Medicine, DOI: 10.1016/j.legalmed.2009.01.014.

Finance Division of the Government of Pakistan (2018) Pakistan Economic Survey 2018-19. Available at: http://www.finance.gov.pk/survey/chapters_19/Economic_Survey_2018_19.pdf

Flavin P., Radcliff B. (2009) Public Policies and Suicide Rates in the American States. Social Indicators Research, 90 (2): 195-209.

Haarr R. N. (2010) Suicidality among battered women in Tajikistan. Violence against women, 16 (7): 764-788.

Hall A. L., Midgley J. (2004) Social Policy for Development. Thousand Oaks, CA: Sage.

Haw C., Hawton K., Gunnel, D., Platt S. (2015) Economic Recession and Suicidal Behavior: Possible Mechanisms and Ameliorating Factors. International Journal of Social Psychiatry, 61 (1): 73-81.

Holden C. (1986) Youth suicide: New Research Focuses on a Growing Social Problem. Science, 233(4766): 839-841.

Keyvanara M., Haghshenas A. (2010) The Sociocultural Contexts of Attempting Suicide among Women in Iran. Health Care for Women International, 31 (9): 771-783.

Khan A. (2018) Why High Hills Have a High Suicide Rate. Herald. Available at: https:/ herald.dawn.com/news/1398672 (accessed 05 March 2020).

Khan M. M. (2005) Marital Satisfaction in Pakistan: A Pilot Investigation. Sexual and Relationship Therapy, 20 (2): 195-209.

Khan M. M., Ahmed A., Khan S. R. (2009) Female Suicide Rates in Ghizer, Pakistan. Suicide and Life-Threatening Behavior, 39 (2):227-230.

Khan M. M., Mahmud S., Karim M, S., Zaman M., Prince M. (2008) Case-control Study of Suicide in Karachi, Pakistan. The British Journal of Psychiatry, 193 (5): 402-405.

Kim C. (2018) The Impacts of Social Protection Policies and Programs on Suicide: A Literature Review. International Journal of Health Services, 48 (3): 512-534. 
Maguire M., Delahunt B. (2017) Doing a Thematic Analysis: A Practical, Step-by-step Guide for Learning and Teaching Scholars. AISHE-J: The All Ireland Journal of Teaching and Learning in Higher Education, 9 (3): 3351-3363.

Mahsud N. K., Ali N. (2018) Suicide and Gender: Case Studies of Suicide Among Females in Hunza Valley. Pakistan Journal of Society, Education and Language, 4 (1): 61-77.

Manning N. (2012) Social Needs, Social Problems, and Social Welfare and Well-being. In: P. Alcock, M. May, S. Wright (eds.) The Student's Companion to Social Policy. $4^{\text {th }}$ Ed. West Sussex: Wiley-Blackwell: 19-25.

Mir S. (2015) Underage, under Law: G-B Lawmakers Block Bill to Ban Child Marriages. The Express Tribune. Available at: https://tribune.com.pk/story/1007117/underage-underlaw-g-b-lawmakers-block-bill-to-ban-child-marriages/ (accessed 16 September 2019).

Ministry of Planning and Development (2016) Annual Plan 2015-16. Balanced Development-Focus on the Less Developed Regions. Available at: https://www.pc.gov.pk/uploads/ docs/Ch15-Development-of-less-developed-areas.pdf (accessed 05 March 2020).

Nazarzadeh M., Bidel Z., Ayubi E., Asadollah K., Carson K. V., Sayehmiri K. (2013) Determination of the Social Related Factors of Suicide in Iran: A Systematic Review and Meta-Analysis. BMC Public Health, 13 (4): 1-9.

Pridmore S. (2000) Suicide and Social Problems. Australasian Psychiatry, 8 (1): 69-70.

Rezaeian M., Dunn G., Leger S. S., Appleby L. (2005) The Ecological Association between Suicide Rates and Indices of Deprivation in English Local Authorities. Social Psychiatry and Psychiatric Epidemiology, 40 (10): 785-791.

Shah S. (2018) Making Sense of the Rising Trends of Suicides in Gilgit Baltistan. Available at: https://pamirtimes.net/2018/09/25/making-sense-of-the-rising-trends-of-suicides-in-gilgitbaltistan/ (accessed 15 August 2021).

Sher S., Dinar H. (2014) Ethnography of Suicide: A Tale of Female Suicides in District Ghizer, Gilgit-Baltistan. The Explorer Islamabad, 1 (6): 207-210.

Sinyor M., Schaffer A., Heisel M. J., Picard A., Adamson G., Cheung C.P., Sareen, J. (2018) Media Guidelines for Reporting on Suicide: 2017 Update of the Canadian Psychiatric Association Policy Paper. The Canadian Journal of Psychiatry, 63 (3): 182-196.

Spicker P. (2011) Generalization and Phronesis: Rethinking the Methodology of Social Policy. Journal of Social Policy, 40 (01): 1-19.

Stuckler D., Basu S., Suhrcke M., Coutts A., McKee M. (2009) The Public Health Effect of Economic Crises and Alternative Policy Responses in Europe: An Empirical Analysis. The Lancet, 374 (9686): 315-323.

Pamir Times (2018) 125 People Have Committed Suicide During the Last 7 Years. Available at: https://pamirtimes.net/2018/02/21/67-people-below-30-years-of-age-have-committed-suicide-in-ghizer-during-the-last-7-years/ (accessed 05 March 2020). 
Rahnuma B., Fangtong J., Khan M., Saddique K., Ahmad I. (2017) Causes of Suicide in Gilgit-Baltistan Region. European Academic Research, (V): 4041-4051.

Tsai A. C., Lucas M., Kawachi I. (2015) Association Between Social Integration and Suicide Among Women in the United States. JAMA Psychiatry, 72(10): 987-993.

Vijayakumar L. (2004). Suicide Prevention: The Urgent Need in Developing Countries. World Psychiatry, 3 (3): 158-159.

WHO (2014) Preventing Suicide: A Global Imperative. Available at: http://www.who.int/ mental_health/suicide-prevention/world_report_2014/en/ (accessed 6 October 2019).

Zutavern J., Kohli M. (2012) Needs and Risks in the Welfare State. In: F. G. Castles, S. Leibfried, J. Lewis, H. Obinger, C. Pierson (eds.) The Oxford Handbook of the Welfare State. Oxford: Oxford University Press: 169-182. 